\title{
The Chaos Based Bankruptcy Model -- Current Status
}

\author{
Annhenrie Campbell \\ California State University, Stanislaus \\ David H. Lindsay \\ California State University, Stanislaus \\ Gökçe Soydemir \\ California State University, Stanislaus \\ Kim Tan \\ California State University Stanislaus
}

This study reexamines whether chaos theory can be used to develop a bankruptcy prediction model. In a 1996 paper, we applied chaos theory to bankruptcy prediction using a pair-matched sample of bankrupt firms and demonstrated that returns of firms nearing bankruptcy would exhibit significantly less chaos, as measured by Lyapunov exponents. The current study extends that work but differs from the earlier study by utilizing a binary logistic regression and bootstrapping to test a recent sample of bankrupt firms and their pair-matches. The current results show that the phenomena observed in 1996 persist.

Keywords: Bankruptcy Model, Chaos, Lyapunov Exponent

\section{INTRODUCTION}

Corporate bankruptcy prediction has piqued the interest of accounting researchers for decades. Beaver published a univariate model in 1966. Altman's widely used multivariate model was published in 1968. Bellovary, Giacomino and Akers examined 165 extant models for assessing corporate bankruptcy. That paper highlights the multitude of methodologies used in the various models which included: multivariate discriminant analysis, logit and probit analysis, neural networks, recursive partitioning and machine learning (Bellovary, et.al., 2007). Due to the significant financial and social consequences of bankruptcy, the possibility of reliable prediction has long captured the attention of investors and creditors.

In 1996, two of the authors of the current paper published A Chaos Approach to Bankruptcy Prediction (Lindsay and Campbell, 1996). That study used a chaos statistic, the Lyapunov exponent, to show that firms approaching bankruptcy exhibit less chaos than pair-matched firms not approaching bankruptcy. This distinction was used to construct a single-variable bankruptcy prediction model with Type 1 and Type 2 error rates of 35\%. Since publication, the article has been cited in the literature fifty- 
five times, but no extension of the method has been attempted. That study was conducted using data from 1983-1992. This current study asks the question, "Does the phenomena observed then still exist?"

\section{LITERATURE REVIEW}

Comprehensive surveys of the bankruptcy prediction literature are provided by Foster and Bellovary, Giacomino and Akers. Foster reviews some 44 journal articles dealing with the problem of bankruptcy prediction. Bellovary, Giacomo and Akers examine 165 models for assessing bankruptcy. Throughout the bankruptcy prediction literature, regardless the methodology used, two issues recur: misclassification errors and tests for external validity (Foster, 1986; Bellovary, et.al., 2007).

Two types of misclassification errors can be observed. A Type 1 error misclassifies a firm which actually will go bankrupt as one which will not go bankrupt. A Type 2 error misclassifies a firm which will not go bankrupt as one which will, indeed, become bankrupt. Type 1 errors have been estimated to be 35 times more costly to decision makers than Type 2 errors (Altman, 1977).

Jones discusses the need to use a validation method to test any newly developed model. Once a model has been developed using one set of data, it should be tested using an independent set of data. Often this is accomplished by testing the model on a hold-out sample (Jones, 1987). However, in studies with a small sample size, bootstrapping is often used as an alternative. Bootstrapping is a testing technique that estimates the properties of the sampling distribution from the sampling data. It does this through random sampling with replacement of the sampling data (Field, 2013).

Foster and Bellovary show that most prediction models are based on a cross-sectional analysis which compares different firms on the basis of financial variables reported at a specific point in time (Foster, 1986; Bellovary, et.al., 2007). Zmijewski isolated the 75 individual ratios most often used in distress prediction studies (Zmijewski, 1983). No theory has yet been successfully proposed to suggest why some variables would be preferable to others (Foster, 1986).

Only occasionally has a bankruptcy prediction study combined a market-based variable with ratios derived from financial statements (White, et.al., 1994). Further, there is no theoretical reason why a time series approach could not be used. Prior to Lindsay and Campbell, no bankruptcy prediction study used a time series methodology based upon chaos, which is also known as non-linear dynamics (Lindsay and Campbell, 1996).

Chaotic systems appear to be random, when in actuality they are deterministic and predictable over short periods of time. They are extremely sensitive to initial conditions, a phenomenon known as the butterfly effect. Chaotic systems have proven quite successful in the prediction of certain endogenously determined catastrophic system failures (Yorke, 1976). Goldberger applied the concept to myocardial infarction (Goldberger, 1990). Stock returns have been shown to exhibit chaotic behavior (Peters, 1991). Etheridge and Sriram argue persuasively that economics and finance researchers have already successfully used chaos theory to study systems such as the stock market and it is exigent that accounting researchers used the methodology (Etheridge and Sriram, 1993) .

\section{HYPOTHESIS DEVELOPMENT}

This study uses the Lyapunov exponent to measure chaos. The exponent measures the rapidity with which a system becomes unpredictable. The larger the exponent the sooner the system becomes unpredictable. Any system with a positive Lyapunov exponent is chaotic. Goldberger suggests that healthy systems exhibit more chaos than unhealthy systems (Goldberger, 1990). The hypothesis of our study is:

$\boldsymbol{H}_{1:}$ The Lyapunov exponent estimated from the time series of stock market returns for firms approaching bankruptcy will be lower than the exponents for firms not approaching bankruptcy. 


\section{METHODOLOGY}

For the years 2009 through 2014, firms which filed for Chapter 11 bankruptcy protection, as well as the date they filed, were identified by an ABI Inform search of the Wall Street Journal. These firms were cross-referenced with those in DataStream. Wall Street Journal firms which lacked a complete set of DataStream daily price data were removed from the sample. To create a control sample, each firm in the bankrupt sample was randomly pair-matched by four digit NAICS code with a non-bankrupt firm.

For each firm in both samples, DataStream daily stock market price data were collected for an early two year window, the period 7-5 years prior to filing for bankruptcy. The daily price data was used to calculate daily returns. The two year period was necessary to generate sufficient observations to apply fractal procedures, about 500 data points. Daily return data were also calculated for a late two-year window, the period 3-1 years prior to filing for bankruptcy. Hence, four sub-samples of data exist: early bankrupt, late bankrupt, early control and late control. Figure 1 illustrates the four time windows.

\section{FIGURE 1}

\section{THE FOUR DATA SUBSETS}

\begin{tabular}{|c|c|}
\hline A & B \\
Bankrupt Firms \\
$7-5$ years prior & $\begin{array}{c}\text { Bankrupt Firms } \\
3-1 \text { years prior }\end{array}$ \\
\hline C & D \\
Pair-Match Firms & Pair Match Firms \\
$7-5$ years prior & 3-1 years prior \\
\hline
\end{tabular}

The Lyapunov exponent for each firm in each window was calculated from the daily return data using the Chaos Data Analyzer software package (Sprott and Rowlands, 1992). The hypothesis leads to the expectation that the early and late Lyapunov exponents would differ for bankrupt firms, with the early exponent being greater than the later exponent. This would not be the case for the pair match firms. For each bankrupt firm, and its pair match, the ratio of early Lyapunov exponent/late Lyapunov exponent is calculated. This ratio is the sole independent variable (covariate) in this paper's bankruptcy prediction model, which is created using a binary logistic regression where the 0,1 dichotomy is not bankrupt/ bankrupt. Hence, not bankrupt/bankrupt is the dependent variable. In lieu of a set aside sample, this study uses bootstrapping (Marais, et.al., 1984).

\section{RESULTS}

The test sample is comprised of thirty-seven firms that declared Chapter 11 bankruptcy between 2009 and 2014, and their pair-matches. Daily returns were calculated for the period of time beginning seven years prior to the bankruptcy filing date. Lyapunov exponents were calculated for both the test firms and their pair-match firms for the early two-year time window (years 7 to 5) and the late two-year time window (years 3 to 1). Table 1 presents the thirty-seven firms and their pair-matches, as well as the Lyapunov exponents for the four time windows. 
TABLE 1

LYAPUNOV EXPONENTS OF BANKRUPT AND PAIR-MATCH FIRMS IN EACH OF THE FOUR TIME WINDOWS

\begin{tabular}{|c|c|c|c|c|c|}
\hline Bankrupt Company & Pair Match & B-Early & B-Late & $\begin{array}{l}\text { PM- } \\
\text { Early }\end{array}$ & $\begin{array}{l}\text { PM- } \\
\text { Late }\end{array}$ \\
\hline Hartmarx & Oxford Industries & 0.405 & 0.362 & 0.372 & 0.345 \\
\hline General Growth Properties & Parkway Properties & 0.392 & 0.352 & 0.381 & 0.386 \\
\hline Visteon & Gentex & 0.356 & 0.366 & 0.415 & 0.396 \\
\hline Six Flags & Cedar Fair & 0.354 & 0.336 & 0.385 & 0.378 \\
\hline Point Blank & Exactech & 0.359 & 0.169 & 0.374 & 0.384 \\
\hline AMBAC Financial & American National & 0.365 & 0.385 & 0.407 & 0.366 \\
\hline Boarders & Barnes and Noble & 0.358 & 0.373 & 0.35 & 0.406 \\
\hline Jackson Hewitt & CBIZ & 0.382 & 0.328 & 0.367 & 0.394 \\
\hline Evergreen Solar & Integrations & 0.452 & 0.39 & 0.394 & 0.359 \\
\hline Syms Corp. & Stein Mart & 0.358 & 0.335 & 0.385 & 0.358 \\
\hline Dynergy & Oge Energy & 0.405 & 0.295 & 0.38 & 0.478 \\
\hline General Maritime & Carolina Bank Holding & 0.385 & 0.365 & 0.452 & 0.409 \\
\hline PMI & Mercury General & 0.444 & 0.358 & 0.338 & 0.302 \\
\hline AMR & Southwest & 0.446 & 0.375 & 0.38 & 0.349 \\
\hline Lee Enterprises & E.W. Scripps & 0.398 & 0.341 & 0.374 & 0.321 \\
\hline Eastman Kodak & Avid Technology & 0.367 & 0.334 & 0.333 & 0.395 \\
\hline Grubb \& Ellis & Thomas Properties & 0.362 & 0.299 & 0.4 & 0.326 \\
\hline Reddy Ice & National Beverage & 0.407 & 0.315 & 0.392 & 0.418 \\
\hline Valence Technology & Sanmina & 0.401 & 0.381 & 0.376 & 0.358 \\
\hline ATP Oil \& Gas & Berry PTL.A & 0.399 & 0.427 & 0.437 & 0.392 \\
\hline Ampal-Amer Isr "A" & Capital Southwest & 0.417 & 0.397 & 0.324 & 0.338 \\
\hline Bakers Footware & Shoe Carnival & 0.32 & 0.334 & 0.406 & 0.378 \\
\hline Satcon & Anadigics & 0.381 & 0.387 & 0.391 & 0.387 \\
\hline Lodgenet & Shennandoah Telecom & 0.396 & 0.387 & 0.39 & 0.4 \\
\hline GMX Resources & Nabor Industries & 0.581 & 0.501 & 0.532 & 0.57 \\
\hline $\begin{array}{l}\text { Triad Utility } \\
\text { Furniture Brands }\end{array}$ & Allstate & 0.35 & 0.579 & 0.506 & 0.532 \\
\hline International & Pier 1 Imports & 0.466 & 0.519 & 0.46 & 0.57 \\
\hline Ecotality & Vanguard Utility & 0.424 & 0.51 & 0.574 & 0.49 \\
\hline GateHouse Media & New York Times & 0.287 & 0.198 & 0.553 & 0.568 \\
\hline Savient Pharmaceuticals & Pfizer & 0.366 & 0.46 & 0.508 & 0.588 \\
\hline James River Coal & Peabody Energy & 0.529 & 0.508 & 0.552 & 0.542 \\
\hline Coldwater Creek Inc & Nordstrom & 0.573 & 0.503 & 0.53 & 0.511 \\
\hline GSE Environmental & Bemi's Company & 0.612 & 0.525 & 0.523 & 0.491 \\
\hline NII Holdings & U.S. Celular Corporation & 0.545 & 0.565 & 0.477 & 0.517 \\
\hline Siga Technologies & Bristol Myers Squibb & 0.544 & 0.446 & 0.554 & 0.535 \\
\hline Alco Stores & Ross Stores & 0.491 & 0.417 & 0.578 & 0.561 \\
\hline Baxano Surgical & Owens and Minor & 0.517 & 0.561 & 0.526 & 0.581 \\
\hline
\end{tabular}


Table 2 shows descriptive statistics of the ratio variable, which is the ratio of the early Lyapunov exponent to the late Lyapunov exponent, and of the bankrupt variable, which is the not bankrupt/ bankrupt 0,1 categorical variable.

TABLE 2

DESCRIPTIVE STATISTICS

\begin{tabular}{llllll}
\hline Variable & $\mathrm{N}$ & Minimum & Maximum & Mean & Standard Deviation \\
\hline Bankrupt & 74 & 0 & 1 & 0.50 & 0.503 \\
Ratio & 74 & 0.6045 & 2.1243 & 1.0546 & 0.1863 \\
\hline
\end{tabular}

Table 3 presents the Pearson correlation coefficient between the independent variable, ratio, and the dependent variable, bankrupt. The correlation is 0.242 , and it is significant at the 0.05 level.

TABLE 3

PEARSON CORRELATION COEFFICIENTS

\begin{tabular}{lll}
\hline & Ratio & Bankrupt \\
\hline Ratio & 1 & $0.242^{*}$ \\
Bankrupt & & 1 \\
\hline
\end{tabular}

* Correlation is significant at the 0.05 level.

It is inappropriate to use a linear regression when the dependent variable in a model is a 0,1 categorical variable. This is because the function is discontinuous; the correct methodology to use is binary regression. Table 4 shows the binary logistic regression results. In linear regressions, $\mathrm{R}$ square is the appropriate measure of how well the model fits the data. In binary logistic regressions, a pseudo $\mathrm{R}$ square serves this function. (Field, 2013). The regression results reveal that the Nagelkerke $\mathrm{R}$ square is 0.089 . The coefficient on the log of the ratio variable (B) is 3.5767 , which is significant at the 0.05 level. The exponential of (B) is 35.394. The log of the constant is -3.737 , which is significant at the 0.05 level. Its exponential is 0.024 .

\section{TABLE 4 BINARY LOGISTIC REGRESSION RESULTS}

Nagelkerke R Square 0.089

Variables in the Equation

\begin{tabular}{lccc}
\hline & B & Sig. & E(B) \\
Ratio & 3.567 & 0.050 & 35.394 \\
Constant & -3.737 & 0.050 & 0.024 \\
\hline
\end{tabular}

The sample is thirty-seven bankrupt firms and their pair matches. Due to the limited size of this sample, a set-aside sample was not created. Instead, bootstrapping was used to generate 15,000 samples. The results of bootstrapping are shown in Table 5. The bootstrap values of the coefficient on the ratio variable and the constant variable remain unchanged from those previously determined. The bootstrap significance on the ratio variable is 0.059 and its significance on the constant is 0.065 . 
TABLE 5

BOOTSTRAP VARIABLES IN THE EQUATION

\begin{tabular}{lcccc}
\hline & & & \multicolumn{2}{c}{$95 \%$ Confidence Interval } \\
& B & Sig. & Lower & Upper \\
\hline Ratio & 3.567 & 0.059 & 0.550 & 8.787 \\
Constant & -3.737 & 0.065 & -9.350 & -0.551 \\
\hline
\end{tabular}

The binary logistic classification table is presented in Table 6 .

TABLE 6

BINARY LOGISTIC CLASSIFICATION TABLE

\begin{tabular}{lccc}
\hline \multicolumn{1}{c}{ Observed } & Not Bankrupt & Predicted & \\
& 22 & Bankrupt & Percent Correct \\
\hline Not Bankrupt & 14 & 15 & 59.5 \\
Bankrupt & & 23 & 62.2 \\
Overall Percentage & & & 60.8 \\
\hline
\end{tabular}

The model correctly predicted that bankrupt firms would go bankrupt 62.2 percent of the time, hence the Type 1 error is 37.8 percent. The model correctly predicted that non-bankrupt firms would not go bankrupt 59.5 percent of the time, hence the Type 2 error is 40.5 percent. Low Type 1 errors are more important than low Type 2 errors. In total, the model correctly predicted the bankruptcy status of a firm 60.8 percent of the time. A naïve model, such as a coin toss, would obtain a 50 percent success rate. For a bankruptcy prediction model with a single independent variable, 60.8 percent is a reasonable success rate.

\section{SUMMARY AND CONCLUSIONS}

The results of this study support the hypothesis that firms approaching bankruptcy display less chaos, as measured by the Lyapunov exponent, than pair-matched firms not approaching bankruptcy. A binary logistic regression was used to develop a bankruptcy prediction model, with coefficients that are significant at the 0.05 level. The predictive ability of the model is a modest 60.8 percent.

The phenomena identified in 1996 still persists. To make further progress, data extending over more years are needed and additional independent variables, such as financial ratios known to be related to bankruptcy, could be added to the model. 


\section{REFERENCES}

Altman, E. I. (1968). Financial Ratios, Discriminant Analysis and the Prediction of Corporate Bankruptcy. Journal of Finance, 23(4), 589-609.

Altman, E. I. (1977). Zeta Analysis: A New Model to Identify Bankruptcy Risk of Corporations. Journal of Banking and Finance, 1(1), 29-54.

American Institute of Physics. (1992). Chaos Data Analyzer. The Academic Software Library of North Carolina State University, Raleigh, N.C.

Beaver, W. H. (1966). Financial Ratios as Predictors of Failure. Journal of Accounting Research, Supplement to Vol. 4, 71-111.

Bellovary, J. L., Giacomino, D. E., \& Akers, M. D. (2007, December). A Review of Bankruptcy Prediction Studies: 1930 to Present. Journal of Financial Education, 33, 1-42.

Etheridge, H. L., \& Sriram, R. S. (1993). Chaos Theory and Nonlinear Dynamics: An Emerging Theory with Implications for Accounting Research. Journal of Accounting Literature, 12, 67-100.

Field, A. (2013). Discovering Statistics Using IBM SPSS Statistics, $4^{\text {th }}$ Edition. Sage Publications, Los Angeles, CA, 773-85.

Foster, G. (1986). Financial Statement Analysis. Prentice-Hall, Englewood Cliffs, N.J.

Goldberger, A. L. (1990). Nonlinear Dynamics, Fractals and Chaos: Applications to Cardiac Electrophysiology. Annals of Biomedical Engineering, 18(2), 195-198.

Jones, F. (1987). Current Techniques in Bankruptcy Prediction. Journal of Accounting Literature, 6, 131164.

Lindsay, D. H., \& Campbell, A. (1996). A Chaos Approach to Bankruptcy Prediction. Journal of Applied Business Research, 12(4), 1-9.

Marais, M. L., Patell, J.M., \& Wolfson, M. A. (1984). The Experimental Design of Classification Models: An Application of Recursive Partitioning and Bootstrapping to Commercial Bank Loan Classifications. Journal of Accounting Research, Supplement to Vol. 22, 87-114.

Peters, E. E. (1991). Chaos and Order in the Capital Markets. John Wiley \& Sons, Inc., New York.

Sprott, J. C., \& Rowlands, G. (1992). Manual for the Chaos Data Analyzer Program. Academic Software Library, North Carolina State University, Raleigh, N.C.

White, G. I., Sodhi, A. C., \& Fried, D. (1994). The Analysis and Use of Financial Statements. John Wiley \& Sons, Inc., New York.

Yorke, J. A. (1976). Simple Mathematical Models with Very Complicated Dynamics. Nature, 2(61), 45967.

Zmijewski, M. E. (1983). Predicting Corporate Bankruptcy: An Empirical Comparison of the Extant Financial Distress Models. Working paper, State University of New York at Buffalo. 